\title{
MORPHOLOGICAL JUSTIFICATION OF THE USE OF ANTIOXIDANTS FOR GROWING POULTRY
}

Key words: geese; ducks; quails; morphology; liver; ultrastructure; hepatocytes; antioxidants; selenium; diisopropylammonium dichloroacetate.

\section{Authors' personal details}

1. Skovorodin Evgeny, Doctor of Veterinary Sciences, Professor, head of Department of morphology, pathology, pharmacy and noncontagious diseases, Federal State Budgetary Educational Institution of Higher Education «Bashkir State Agrarian University», 450001, Ufa, 50-letiya Oktyabrya St., 34, phone: +7 (347) 228-28-77, e-mail: skovorodinen@mail.ru.

2. Bazekin George, Candidate of Biological Sciences, Dean of faculty of biotechnology and veterinary medicine, Federal State Budgetary Educational Institution of Higher Education «Bashkir State Agrarian University», 450001, Ufa, 50-letiya Oktyabrya St., 34, phone: +7 (347) 228-28-77, e-mail: george.bazekin@, rambler.ru.

3. Bronnikova Guzel, Post-graduate student, Department of morphology, pathology, pharmacy and noncontagious diseases, Federal State Budgetary Educational Institution of Higher Education «Bashkir State Agrarian University», 450001, Ufa, 50-letiya Oktyabrya St., 34, phone: +7 (347) 228-28-77, e-mail: bronnikova.g @bashkortostan.ru.

4. Dyudbin Oleg, Candidate of Veterinary Sciences, senior lecturer, Department of morphology, pathology, pharmacy and noncontagious diseases, Federal State Budgetary Educational Institution of Higher Education «Bashkir State Agrarian University», 450001, Ufa, 50-letiya Oktyabrya St., 34, phone: +7 (347) 228-2877, e-mail: d-oleg7@mail.ru.

The study objective is to examine the impact of feed supplements, containing natural antioxidants (selenium) and synthetic antioxidant (diisopropylammonium dichloroacetate). The performed studies allowed to determine positive influence of the antioxidants on growth and development of the meat poultry (musky ducks, geese of the Hungarian white breed, quail), whose body mass increased by $5-10 \%$ in comparison with the control parameters. The use of antioxidants prevents from development of fatty, hydropic and parenchymal degeneration, hepatocyte and epithelial cells, necrosis of the bile ducts, connective tissue proliferation with its further

(C) Сковородин Е.Н., Базекин Г.В., Бронникова Г.З., Дюдьбин О.В. fibrosis. The ultrastructural hepatocytes studies of the control group poultry showed the disorders of the mitochondria structure and granular endoplasmic reticulum. The mitochondria underwent intumescence, polymorphism, proliferation and damage. The antioxidants prevent defragmentation and acinar transformation of the granular endoplasmic reticulum, vacuolization, emerging of lipid drops and cytoplasmic myelin-like structures. This study showed that it is more effective to use a well-digested, fast-acting multivitamin antioxidant complex with selenium immediately after hatching.

УДК 631.53.01:612.014.464

DOI: $10.31563 / 1684-7628-2020-53-1-125-131$

А.В. Богданов, В.В. Евченко, С.Ю. Попова

\section{ОПРЕДЕЛЕНИЕ ВРЕМЕНИ СНИЖЕНИЯ КОНЦЕНТРАЦИИ ОЗОНА ДО УРОВНЯ ПДК ПРИ ОБОСНОВАНИИ ПАРАМЕТРОВ УСТАНОВКИ ДЛЯ ПРЕДПОСЕВНОЙ ОБРАБОТКИ СЕМЯН}

\section{Ключевые слова: обработка семян; озоно-воздушная смесь; озонирование; генератор озона; ре- жимы обработки, предельно-допустимая концентрация.}

Увеличение объемов продовольственной продукции растениеводства непосредственно связано с повышением урожайности сельскохозяйственных культур. Повышение урожайности 
зависит от многих факторов, в том числе от всхожести семян той или иной сельскохозяйственной культуры. Одним из путей, увеличивающих всхожесть, является предпосевная обработка семян [1-5]. Существуют различные методы предпосевной обработки семян: биологические, химические и физические. Все они оказывают стимулирующее влияние на семена, что приводит к повышению их всхожести, росту и развитию растений, и следовательно, урожайности самих культур [6-10].

Одним из экологически чистых и экономически выгодных направлений является озонирование семян, которое относится к физическим методам предпосевной обработки [11-16]. Но озонирование семян требует обоснования режимов обработки и повышенной безопасности, так как высокие концентрации озона могут нанести ущерб здоровью человека (обслуживающему персоналу) вплоть до получения профессиональных заболеваний.

Для обоснования режимов обработки семян озоном нами разработана соответствующая установка (рисунок 1), на которую получен патент на полезную модель [17]. Установка включает в себя камеру для обработки семян озоном 7, выполненную из герметичного короба с плотно закрывающейся крышкой 4. Внутри установки расположены генератор озона 2 с газопроводом 3 , съемные контейнеры 9 для размещения семян, датчик 8, передающий информацию о концентрации газа на блок управления 1. Также имеются устройства 10 и 6 соответственно для выпуска озоно-воздушной смеси и впуска воздуха. Устройство впуска воздуха 6 соединено с вентилятором 5 [17, 18].

Работа установки (рисунок 1) начинается с того, что семена в отдельных съемных контейнерах 9 (чашки Петри) располагают в камере для обработки 7 и герметично закрывают крышкой 4. После этого приводится в действие генератор озона 2, и озон направляется через газопровод 3 в камеру для обработки семян 7. При этом устройство 10 выпуска озоно-воздушной смеси находится в открытом состоянии, а устройство 6 впуска воздуха - в закрытом. Далее озон вытесняет воздух из камеры обработки 7 в атмосферу через устройство 10. Концентрация озона в камере обработки 7 повышается. С датчика 8, находящегося в камере для обработки 7, передается информация о концентрации озона на блок управления 1. Когда концентрация озона становится равной требуемой величине, устройство 10 выпуска озоно-воздушной смеси переводится в закрытое состояние. Семена определенное время подвергаются озонированию. После окончания озонирования продувается камера обра- ботки 7. При этом включается вентилятор 5, а устройства 10 и 6 для выпуска озоно-воздушной смеси и впуска воздуха переводятся в открытые состояния. Когда концентрация озона в камере обработки 7 становится равной предельно допустимой концентрации (ПДК), открывается крышка 4 для извлечения семян $[17,18]$.

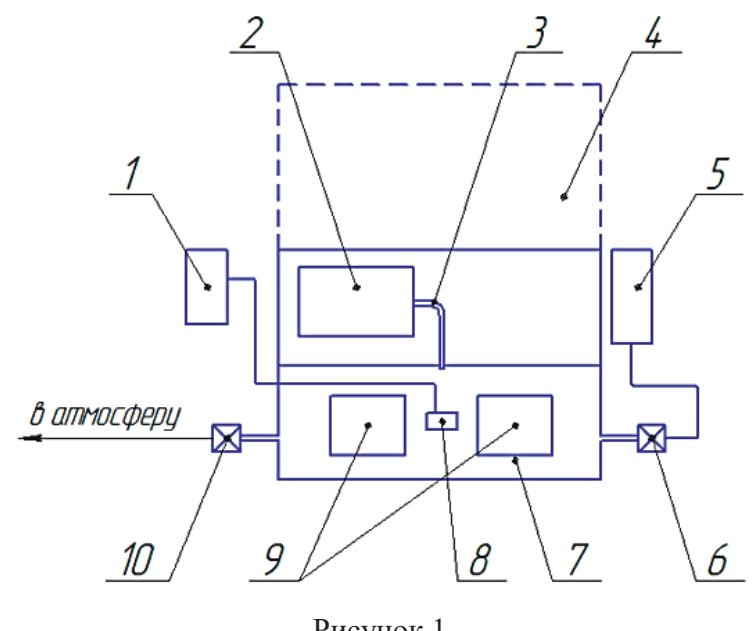

Схема установки для озонирования семян: 1 - блок управления; 2 - генератор озона; 3 - газопровод; 4 - крышка; 5 - вентилятор; 6 - устройство впуска воздуха; 7 - камера для обработки; 8 - датчик; 9 - съемные контейнеры; 10 - устройство выпуска озоно-воздушной смеси

Обоснование основных параметров установки прежде всего сводится к определению:

- объема камеры для обработки семян, позволяющего проводить исследования в соответствие с ГОСТ 12038-84 «Семена сельскохозяйственных культур. Методы определения всхожести» [19];

- времени снижения концентрации озона в камере обработки до уровня ПДК после проведения озонирования семян.

Объем камеры $V_{\kappa}$ для обработки семян можно рассчитать по ранее полученной нами формуле [18]:

$$
V_{\kappa}=\left(4 \cdot d_{n}+5 \cdot \ell\right) \cdot\left(d_{n}+2 \cdot \ell\right) \cdot\left(h_{2}+h\right),
$$

где $d_{n}$ - диаметр чашки Петри, м $\left(d_{n}=0,11 \mathrm{м}\right)$; $\ell$ - расстояние между чашками Петри и расстояние от стенок камеры для обработки семян озоном до чашек Петри, м $(\ell=0,01 \mathrm{~m}) ; h_{2}$-высота генератора озона, м $\left(h_{2}=0,2 \mathrm{м}\right) ; h$-запас высоты в камере для обработки семян озоном, м $(h=$ $0,05 \mathrm{M})$.

С учетом численных значений объем камеры $V_{\kappa}$, подсчитанный по формуле (1), составит $0,016 \mathrm{~m}^{3}\left(V_{\kappa}=0,016 \mathrm{~m}^{3}\right)$.

Найденный объем камеры $V_{\kappa}$ также важен для определения времени снижения концентрации озона в камере озонирования до уровня ПДК после проведения обработки семян. Дело в том, что обработка семян озоном проводится 
при концентрациях, которые существенно выше ПДК. При этом предельно-допустимая концентрация озона составляет 0,1 мг/ м $^{3}$ [20]. В связи с этим для исключения повреждения здоровья обслуживающего персонала поднимать крышку установки с целью извлечения семян после их обработки допускается только при снижении концентрации озона до значения ПДК. Это достигается включением вентилятора установки на определенное время и переводом устройств для выпуска озоно-воздушной смеси и впуска воздуха в открытые состояния. При этом подаваемый вентилятором воздух вытеснит озоновоздушную смесь из камеры озонирования за определенное время.

Время снижения концентрации озона до уровня ПДК после проведения озонирования можно определить по выведенной нами теоретической зависимости [18]:

$$
t_{c}=k \cdot \frac{c \cdot V_{\kappa}}{\Pi_{B}},
$$

где $t_{c}$ - время, необходимое для снижения концентрации озона до ПДК после проведения обработки семян, мин; $\Pi_{6}-$ производительность вентилятора, м $3 /$ мин; $c$ - концентрация озона

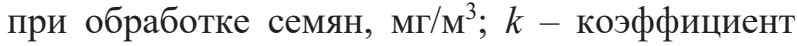
пропорциональности, учитывающий конструкцию установки, проходные сечения шлангов и вентилей и др., $\mathrm{m}^{3} / \mathrm{мг}$.

Для расчета времени $t_{c}$ по зависимости (2) необходимо знать численные значения концентрации озона, объема камеры озонирования, производительности вентилятора, а также коэффициента пропорциональности $k$. Коэффициент $k$ можно определить на основе экспериментальных исследований с предлагаемой установкой (рисунок 2).

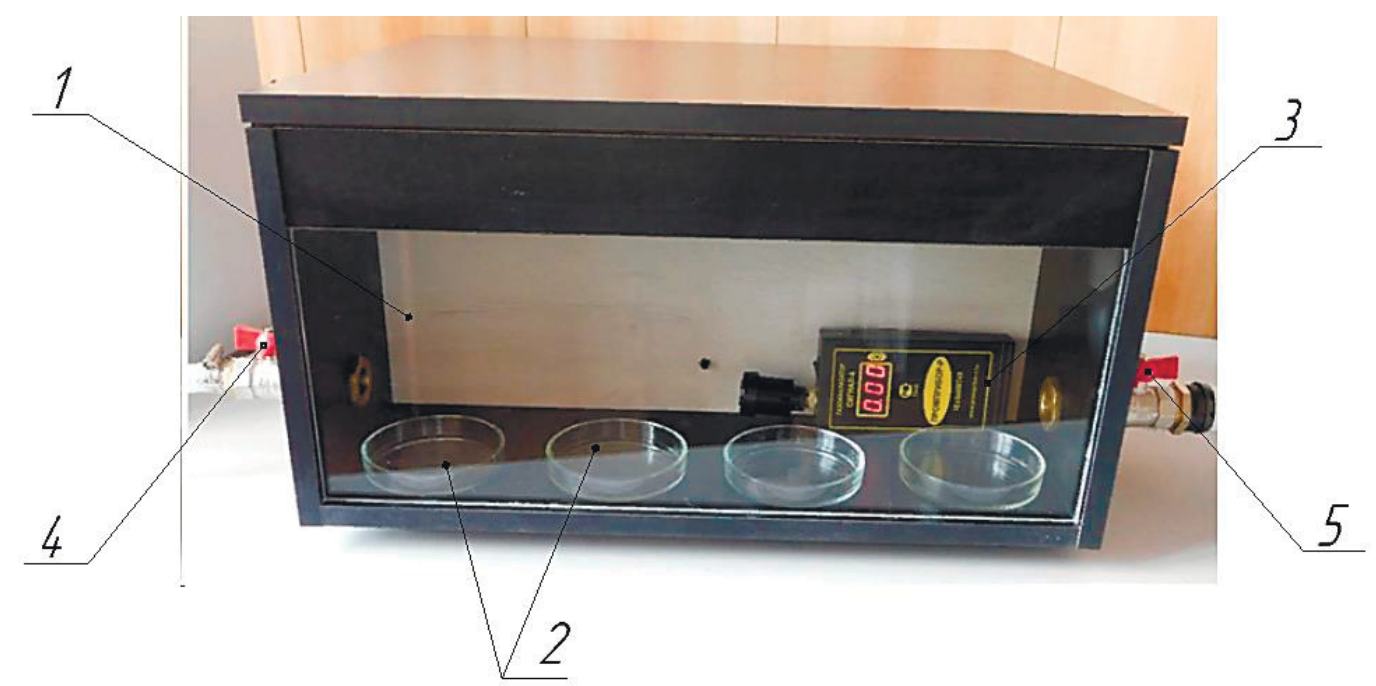

Рисунок 2

Установка для озонирования семян: 1 - камера для обработки семян; 2 - съемные контейнеры;

3 - газоанализатор озона «Сигнал-4Э»; 4 - вентиль выпуска озоно-воздушной смеси; 5 - вентиль впуска воздуха

Для определения времени снижения концентрации озона до уровня ПДК в камере для обработки семян эксперименты проводились следующим образом. При герметично закрытой крышке включался генератор озона типа GL3188, расположенный в тыльной части установки для озонирования семян. После достижения заданной концентрации озона генератор отключался. Открывались вентили впуска воздуха и выпуска озоно-воздушной смеси, включался вентилятор и с помощью секундомера механического СОПпр-2a-3 регистрировалось время снижения концентрации озона до уровня ПДК. Концентрация озона в камере для обработки семян фиксировалась с помощью газоанализатора озона «Сигнал-4Э».

Экспериментальные исследования по определению времени снижения концентрации озона до уровня ПДК в камере для обработки семян проводились при концентрациях озона $9 \mathrm{мг} / \mathrm{M}^{3}$, $6 \mathrm{мг} / \mathrm{M}^{3}$ и 3 мг $/ \mathrm{M}^{3}$, используемых при исследованиях, с четырехкратной повторностью. Средние значения результатов экспериментов представлены в таблице 1 .

Таблица 1 Время снижения концентрации озона до уровня ПДК в камере для обработки семян

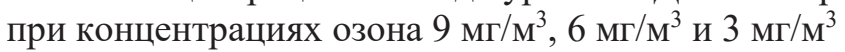

\begin{tabular}{|c|c|c|c|}
\hline Концентрация озона $c$, мг/ $\mathrm{M}^{3}$ & 9 & 6 & 3 \\
\hline $\begin{array}{c}\text { Время снижения концентрации озона до уровня ПДК } \\
\text { после проведения озонирования в камере для обработки семян } t_{c} \text {, мин }\end{array}$ & 1,38 & 1,14 & 0,57 \\
\hline
\end{tabular}


Как видно из таблицы 1, время снижения концентрации до уровня ПДК зависит от концентрации озона в камере для обработки семян. По данным таблицы 1 с помощью системы MS Excel был построен график зависимости времени снижения концентрации озона до уровня ПДК в камере для обработки семян (рисунок 3). Для большей наглядности при построении графика также использовалась точка, соответствующая концентрации озона $c=0 \mathrm{M \Gamma} / \mathrm{M}^{3}$ (при от- сутствии озона в камере для обработки семян). При этом время снижения концентрации озона было принято равным нулю.

Рисунок 3 показывает, что с повышением концентрации озона в камере для обработки семян время $t_{c}$ увеличивается. Причем наблюдается линейная зависимость, подчиняющаяся уравнению регрессии:

$$
t_{c}=0,157 \cdot c+0,066 .
$$

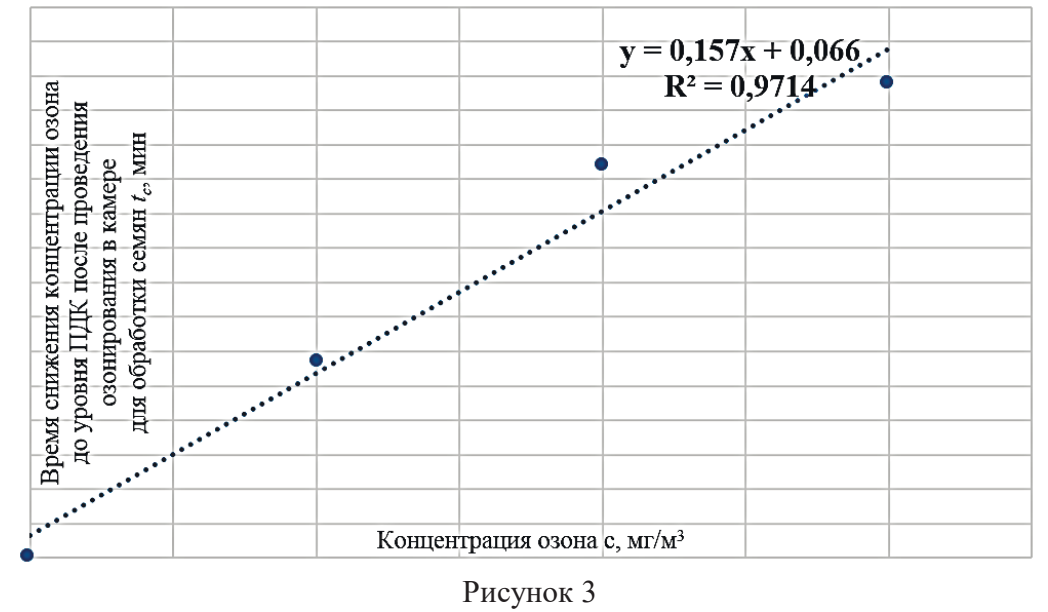

Время снижения концентрации озона до уровня ПДК в камере для обработки семян

На основании полученных результатов можно определить коэффициент пропорциональности $k$, который найдется из формулы (2):

$$
k=\frac{t_{c} \cdot \Pi_{b}}{c \cdot V_{\kappa}} .
$$

Решая совместно уравнение (3) и равенство (4) при концентрациях озона $9 \mathrm{Mr} / \mathrm{M}^{3}, 6 \mathrm{M \Gamma} / \mathrm{M}^{3}$ и $3 \mathrm{M \Gamma} / \mathrm{M}^{3}$, получим среднее значение коэффициента пропорциональности $k$ при производительности вентилятора $\Pi_{B}=32,5 \mathrm{~m}^{3} /$ мин и объеме камеры для обработки семян озоном $V_{k}=0,016 \mathrm{~m}^{3}$. При этом величина коэффициента пропорциональности $k$ составляет $346,4 \mathrm{~m}^{3} / \mathrm{M \Gamma}\left(k=346,4 \mathrm{~m}^{3} / \mathrm{M \Gamma}\right)$.
Полученное значение коэффициента пропорциональности $k$ позволяет сравнить теоретическую (2) и экспериментальную (3) зависимости (рисунок 4).

Как видно из рисунка 4 , теоретическая и экспериментальная прямые имеют небольшие расхождения (не более $6 \%$ ) в диапазоне концентраций озона (от 3 мг $/ \mathrm{M}^{3}$ до 9 мг $/ \mathrm{M}^{3}$ ), используемых при исследованиях. Поэтому предложенную теоретическую зависимость (3) можно применять для расчета времени снижения концентрации озона до уровня ПДК в камере для обработки семян.

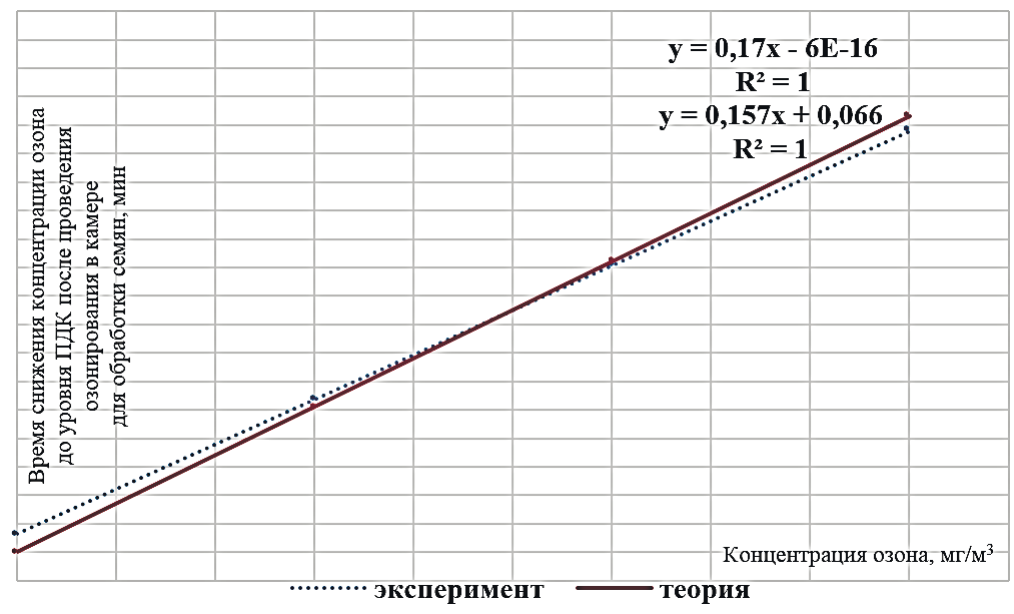

Рисунок 4

Время снижения концентрации озона до уровня ПДК в камере для обработки семян (по теоретической и экспериментальной зависимостям) 
Нужно отметить, что рассчитанное по формуле (2) время $t_{c}$ уже использовалось при проведении экспериментов для обоснования режимов озонирования семян кабачка [21].

Обоснование режимов озонирования посредством рассматриваемой установки необхо- димо для предпосевной обработки различных семян на промышленных устройствах. Обработка семян при обоснованных режимах озонирования позволит повысить их всхожесть и урожайность сельскохозяйственных культур.

\section{Библиографический список}

1. Огнев, В.Н. Применение экологически безопасных способов предпосевной обработки семян для защиты ярового ячменя против корневых гнилей [Текст] / В.Н. Огнев // Научный потенциал - аграрному производству: материалы Bcерос. науч.-практ. конф. (26-29 февр. 2008 г.) / ФГОУ ВПО Ижевская ГСХА. Ижевск: Ижевская ГСХА, 2008. Т. 1. С. 172-176.

2. Оленюк, А.А. Анализ методов повышения урожайности культурных растений [Электронный ресурс] / А.А. Оленюк, Л.Н. Михайлова, А.Н. Мороз. Режим доступа: http://old. khntusg.com.ua/files/sbornik/vestnik_129/48.pdf (дата обращения: 11.12.2019).

3. Пат. 2248111 РФ МПК ${ }^{7}$ А01C 1/00. Способ обработки семян сельскохозяйственных культур [Текст] / Д.А. Нормов, С.В. Оськин, А.А. Шевченко, Е.А. Сапрунова; заявитель и патентообладатель Кубанский Государственный аграрный университет. № 2003123158; заявл. 22.07.2003; опубл. 20.03.2005. Бюл. № 8.

4. Савельев, В.А. Предпосевная обработка семян зерновых культур [Текст]: монография / В.А. Савельев. Саратов: Вузовское образование, 2014. 197 c.

5. Старухин, Р.С. Метод предпосевной обработки семян с использованием эллиптического электромагнитного поля [Текст] / Р.С. Старухин, И.В. Белицын, О.И. Хомутов // Ползуновский вестник. 2009. № 4. С. 97-103.

6. Влияние лазерной обработки на семена яровой пшеницы [Электронный ресурс] / О.Г. Долговых, В.В. Красильников, Р.Р. Газтдинов // Инженерный вестник Дона: электрон. науч. журн. Режим доступа: http://www.ivdon.ru/ magazine/archive/n4p2y2012/1422 (дата обращения: 11.12.2019).

7. Володин, В.И. Стимуляция прорастания семян с помощью ультразвука и гиббереллина [Текст]: автореф. дис. ... канд. биол. наук / В.И. Володин. Л., 1963.

8. Высоцкая, Е.А. Анализ технологических приемов и технических средств предпосевной обработки семян биопрепаратами [Текст] / Е.А. Высоцкая, М.А. Крекотень // Вестник Воронежского государственного аграрного университета. 2015. № 4 (47). Ч. 2. С. 100-104.

9. Как помочь семенам расти [Электронный ресурс]. Режим доступа: http://www. activestudy.info/kak-pomoch-semenam-rasti (дата обращения: 11.12.2019).

10. Евченко, В.В. Анализ методов предпосевной обработки семян [Текст] / В.В. Евченко // Сервис технических систем - основы безопасного функционирования машин и оборудования предприятий АПК. Материалы международной научно-практической конференции Института агроинженерии. Челябинск: Южноуральский ГАУ, 2018. С. 333-338.

11. Богданов, А.В. Теоретические предпосылки к изучению вопроса озонирования семян [Текст] / А.В. Богданов, Е.Е. Евченко // Молочнохозяйственный вестник. 2018. № 1 (29). С. 8 16.

12. Авдеева, В.Н. Обработка семян пшеницы озоном с целью повышения их посевных качеств [Текст] / В.Н. Авдеева, Ю.А. Безгина // Sworld: сб. науч. тр. 2015. Т. 17. № 2. С. 25-29.

13. Горский, И.В. Обработка семян пшеницы озонированным воздухом [Текст]: дис. ... канд. техн. наук / И.В. Горский. М., 2004.

14. Дубцова, А.А. Особенности проявления ростовых процессов семян льна после озонирования [Текст] / А.А. Дубцова // Научные и инновационные разработки молодых ученых-аграриев. 2015. С. 68-72.

15. Нормов, Д.А. Применение озона для предпосевной обработки семян [Текст] / Д.А. Нормов, Е.А. Федоренко // Сахарная свёкла. 2009. № 1. С. 17-24.

16. Шевченко, А.А. Параметры электроозонирования для предпосевной обработки семян кукурузы [Текст]: автореф. дис. ... канд. техн. наук / А.А. Шевченко. Краснодар, 2005.

17. Пат. 186528 РФ МПК ${ }^{7}$ А01C 1/00. Установка для озонирования семян [Текст] / А.В. Богданов, В.В. Евченко, В.В. Колягин, С.Ю. Попова; заявитель и патентообладатель Южно-Уральский государственный аграрный университет. № 2018127950, заявл. 30.07.2018; опубл. 23.01.2019, бюл. № 3 .

18. Богданов, А.В. Обоснование установки озонирования семян для определения рациональных режимов их обработки и повышения безопасности обслуживающего персонала [Текст] / А.В. Богданов, В.В. Евченко, С.Ю. Попова // АПК России. 2019. Т. 26. № 4. С. 500-504. 
19. ГОСТ 12038-84. Семена сельскохозяйственных культур. Методы определения всхожести [Текст].

20. ГОСТ 12.1.005-88. Система стандартов безопасности труда (ССБТ). Общие санитарногигиенические требования к воздуху рабочей зоны [Текст].
21. Bogdanov A.V., Evchenko V.V., Popova S.Yu. Experimental studies on vegetable marrow seeds ozonation using laboratory equipment: E3S Web of Conferences (international Conference on Modern Trends in Manufacturing Technologies and Equipment, ICMTMTE 2019; Sevastopol), volume 126, 00002, 30 October 2019.

\section{Сведения об авторах}

1. Богданов Андрей Владимирович, доктор технических наук, доцент, профессор кафедры технического сервиса машин, оборудования и безопасности жизнедеятельности, ФГБОУ ВО «Южно-Уральский государственный аграрный университет», 454080, г. Челябинск, пр. Ленина, 75, тел.: +7 (351) $265-$ 56-08, e-mail: bav-64@mail.ru.

2. Евченко Виктория Вадимовна, аспирант кафедры технического сервиса машин, оборудования и безопасности жизнедеятельности, ФГБОУ ВО «Южно-Уральский государственный аграрный университет», 454080, г. Челябинск, пр. Ленина, 75, тел.: +7 (351) 265-56-08, e-mail: vikylya1992-11@ mail.ru.

3. Попова Светлана Юрьевна, кандидат технических наук, доцент, доцент кафедры технического сервиса машин, оборудования и безопасности жизнедеятельности, ФГБОУ ВО «Южно-Уральский государственный аграрный университет», 454080, г. Челябинск, пр. Ленина, 75, тел.: +7 (351) $265-$ 56-08, e-mail: vetochka.79@mail.ru.

Увеличение объемов продовольственной продукции растениеводства непосредственно связано с повышением урожайности сельскохозяйственных культур. Повышение урожайности зависит от многих факторов, в том числе от всхожести семян той или иной сельскохозяйственной культуры. Одним из путей, увеличивающих всхожесть, является предпосевная обработка семян. Экологически чистым и экономически выгодным направлением считается озонирование семян, которое относится к физическим методам предпосевной обработки. Но озонирование семян требует обоснования режимов обработки и повышенной безопасности, так как высокие концентрации озона могут нанести ущерб здоровью человека. Для обоснования режимов обработки семян озоном авторами статьи разработана соответствующая установка, на которую получен патент на полезную модель. В статье приводятся схема и принцип работы установки. Экспериментальным путем определено время снижения кон- центрации озона в камере озонирования до уровня ПДК при нагнетании воздуха посредством вентилятора. Получены соответствующие уравнения регрессии и найден коэффициент пропорциональности для ранее полученной теоретической зависимости. Это позволяет рассчитывать время снижения концентрации до уровня ПДК в зависимости от начальной концентрации озона в камере обработки семян предлагаемой установки, объема самой камеры и производительности вентилятора. Зная величину времени снижения концентрации озона до уровня ПДК, можно безопасно проводить экспериментальные исследования по обоснованию режимов озонирования семян различных сельскохозяйственных культур. Рассчитанное время снижения концентрации уже использовалось при проведении экспериментов для обоснования режимов озонирования семян кабачка. При этом эксперименты были проведены без нанесения ущерба здоровью обслуживающему персоналу.

A. Bogdanov, V. Evchenko, S. Popova

\section{TIMING THE REDUCTION OF THE OZONE CONCENTRATION TO MAC LEVEL WHEN PROVIDING A RATIONALE FOR THE PARAMETERS OF THE PRESOWING SEED TREATMENT MACHINE}

Key words: seed treatment; ozone-air mixture; ozonation; ozone generator; treatment modes, maximum allowable concentration (MAC).

\section{Authors' personal details}

1. Bogdanov Andrey, Doctor of Technical Sciences, Associate Professor, Professor of the Department of Technical Maintenance, of Machinery, Equipment and Life Safety, South Ural State Agrarian University, 454080, Chelyabinsk, prospect Lenina, 75, phone: +7 (351) 265-56-08, e-mail: bav-64@mail.ru. 
2. Evchenko Victoria, Post-graduate student of the Department of Technical Maintenance, of Machinery, Equipment and Life Safety, South Ural State Agrarian University, 454080, Chelyabinsk, prospect Lenina, 75, phone: +7 (351) 265-56-08, e-mail: vikylya1992-11@mail.ru.

3. Popova Svetlana, Candidate of Technical Sciences, Associate Professor, Associate Professor of the Department of Technical Maintenance, of Machinery, Equipment and Life Safety, South Ural State Agrarian University, 454080, Chelyabinsk, prospect Lenina, 75, phone: +7 (351) 265-56-08, e-mail: vetochka.79@ mail.ru.

The increase in crop food production is directly related to the increase in crop yields. Higher yields depend on many factors, including seed germination of a specific crop. Pre-sowing seed treatment is one of the ways to increase seed germination. Ozone treatment of seeds is an environmentally friendly and cost-effective technique. The method belongs to the physical methods of pre-sowing treatment. Ozone treatment of seeds requires a rationale for the treatment modes and safety provisions. To provide the rationale a machine for the ozone treatment of seeds was developed. The machine is patented as a utility model. The paper provides a description of the machine design and operation. The experiment has resulted in timing the reduction of the ozone

(C) Богданов А.В., Евченко В.В., Попова С.Ю. concentration in the ozone treatment chamber to the MAC level when air is forced by the fan. The corresponding regression equations were deduced and the proportionality coefficient for the previously obtained theoretical dependence was found. They help time the reduction of the ozone concentration to the MAC level depending on the initial concentration of ozone in the seed treatment chamber, the chamber capacity, and the fan performance. With the right timing, experimental studies on justifying ozone treatment modes in various crops can be safely conducted. The timing was successfully used to justify an ozone treatment mode for marrow squash seeds. The experiment was conducted without damage to the personnel's health.

УДК 628.1, 663.63

DOI: $10.31563 / 1684-7628-2020-53-1-131-141$

А.И. Егоров, Д.П. Юхин

\section{ОЦЕНКА НЕГАТИВНОГО ВОЗДЕЙСТВИЯ ДЕМИНЕРАЛИЗОВАННОЙ ВОДЫ НА ЗДОРОВЬЕ ЧЕЛОВЕКА И ИНЖЕНЕРНЫЕ КОММУНИКАЦИИ, ПОСРЕДСТВОМ УЧАСТИЯ БАРОМЕМБРАННОЙ ТЕХНОЛОГИИ В УДАЛЕНИИ КРЕМНИЯ И БОРА}

Ключевые слова: очистка воды; водоподготовка; природная вода; соли; кремний; бор; обескремнивание; обесборивание; баромембранный метод; обратный осмос; деминерализация; обессоливание; питьевая вода; здоровье человека; коррозионность; агрессивность; нестабильность воды; стабилизационная обработка; минерализация воды; индекс карбонатного насыщения (Ланжелье); модельные организмы; контроль качества воды.

Введение. Вода - это основа жизни на Земле и незаменимый энергетический ресурс для огромного количества технологий во всех отраслях промышленности. Общий объем ресурсов пресных вод Российской Федерации оценивается в 7770,6 км³, который постоянно сокращается.

«Доступ к безопасной воде - универсальная необходимость... и основное право человека», задекларировала директор Всемирной организации здравоохранения (ВО3) Гру Харлем Брунтланн в речи, посвященной Международному водному дню 22 марта 2001 г., сфокусировав внимание на актуальности этой проблемы. В течение последних 50 лет ВОЗ занимается каче- ством питьевой воды и его влиянием на здоровье людей. Одна из основных целей $\mathrm{BO} 3$ и ее членов состоит в обеспечении соблюдения права человека на доступ к питьевой воде: «Все люди независимо от стадии развития и социальных, классовых или экономических условий имеют право на источник безопасной питьевой воды». Основная функция ВОЗ в достижении этой цели - «предлагать нормы и давать рекомендации в отношении международных вопросов влияния качества воды на здоровье» [1].

В результате антропогенного влияния на окружающую среду с появлением новых отраслей промышленности и современных технологий, совершенствования существующих техно- 